\title{
A Non-Destructive Investigation of two Cypriot Bronze Age Knife Blades using Neutron Diffraction Residual Stress Analysis
}

\author{
Christopher Davey ${ }^{1, a^{*}}$, David Saunders ${ }^{1, b}$, Vladimir Luzinn ${ }^{2, ~ c}$, Joseph Bevitt ${ }^{2, ~ d, ~}$ \\ Jennifer Webb ${ }^{3, e}$, James Donlon ${ }^{3, f}$ and Mihail lonescu ${ }^{2, g}$ \\ ${ }^{1}$ Australian Institute of Archaeology, La Trobe University, VIC 3086, Australia \\ ${ }^{2}$ Australian Nuclear Science and Technology Organisation, Locked Bag 2001, Kirrawee DC, \\ NSW, 2232 Australia \\ ${ }^{3}$ Department of Archaeology and History, La Trobe University, VIC 3086, Australia \\ adirector@aiarch.org.au, bspedtwo@gmail.com, vll@ansto.gov.au, djbv@ansto.gov.au, \\ ejenny.webb@latrobe.edu.au, jamesrobertdonlon@gmail.com, ${ }^{9}$ mio@ansto.gov.au
}

\section{Keywords: Ancient Bronzes, Neutron Stress Measurements}

\begin{abstract}
This paper presents the results of a residual stress analysis that is part of a wider study of Cypriot Bronze Age knife and other weapon blades from a corpus of artefacts held by a number of institutions in Australia. The current focus is on knives from Early/Middle Bronze Age burial sites at Bellapais Vounous, Cyprus; a significant number of the blades were found on excavation to be bent. The aim of the study was to provide, by means of non-destructive neutron residual stress analysis, likely insights into fabrication methodologies of the knives and determine the stage in the life of each knife blade at which bending occurred. Two Vounous knives from the Australian Institute of Archaeology collection, one measurably bent and the other severely bent and broken, were studied using neutron diffractometer KOWARI to establish the residual stress profiles through the thickness of the knives at several locations. Since the knives were $1-2 \mathrm{~mm}$ thick at their thinnest sections, a very high through-thickness spatial resolution of $0.1 \mathrm{~mm}$ was used to resolve the residual stress profiles. The experimental data from the knives suggested forging/hammering as a possible method of fabrication of functional (hard edge) knife blade. Most significantly, however, the post fabrication bending of both knives at ambient temperature was established. The residual stress data for the two knives were considered in the context of reported metallurgical studies and the archaeological information from Cypriot Bronze Age sites.
\end{abstract}

\section{Introduction}

The work reported in this paper brings together some aspects of the physical metallurgy of a specific corpus of artefacts from the well-documented burial site Bellapais Vounous, Fig. 1, an Early/Middle Bronze Age site in Cyprus (c 2450-1700 $\mathrm{BCE})$. The site is a cemetery of over 160 tombs that were excavated by a number of archaeologists; notably Dikaios [3] and Stewart and Stewart [4]. Post excavation, the metallic artefacts, (including spearhead, knives and razors) and others of pottery were

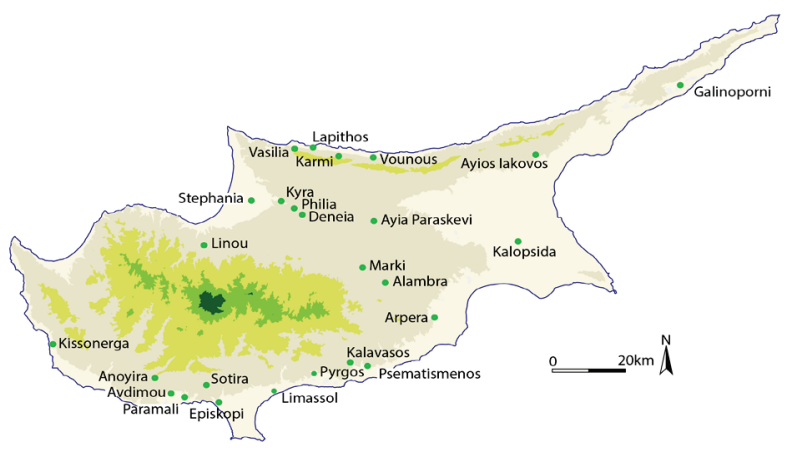

Fig. 1. Map of Cyprus showing the location of Bellapais Vounous and other Early/Middle Bronze Age sites (after [1, 2]). distributed to a small number of museums in England and Australia. Many of the Vounous artefacts available for study in Australia are provenanced to specific tombs at the site; and thus can be used to 
provide insights into origins of raw material, use of the material, fabrication methods and treatment of the artefacts when used as burial items. These objects belong to early phase metallurgy in Cyprus and therefore offer insight into the nature and origins of its ancient copper industry. One particular feature of the Early/Middle Cypriot Bronze Age burials is that a significant number of knife and spear blades from this, and other, Bronze Age sites were found, on excavation, to be bent. Many scholars have noted the deliberate destruction or disabling of metal weapons in burial contexts (e.g. $[2,5-7])$. Often referred to as 'ritual killing', the act of disabling is believed to have taken place at the burial site and assumed to have been intended to enable the weapons to accompany the dead and perhaps ensure that they could not be used as weapons after burial. Any insights into the fabrication route of the knives and determining the stage in the life of each knife blade at which bending occurred are highly desirable.

There have been limited metallurgical studies of Vounous metallic artefacts and much of the work to date has provided elemental analyses [1, 8], $\mathrm{Pb}$ isotope analysis [1] and metallography [9]. Through the metallographic analysis [9], there is a notion that the blades/weapons had been cold worked from original states, most likely cast blanks, annealed and then additionally cold worked to their final form. Since residual stresses are intrinsically linked to each these processes, there is a potential to provide new and corroborating information about the fabrication and treatment or handling of the Early/Middle Bonze Age bronze artefacts from fabrication and post-fabrication perspectives and possibly to support the view of ritual bending practices at some ancient Cypriot burials. Although application of neutron diffraction to study ancient bronzes has been reported [10], there are currently limited data and, to the authors' knowledge, no studies of residual stresses or textures within the corpus of Vounous artefacts. The current paper reports the results of the application of non-destructive neutron diffraction methods to two Bronze Age knife blades from Vounous.

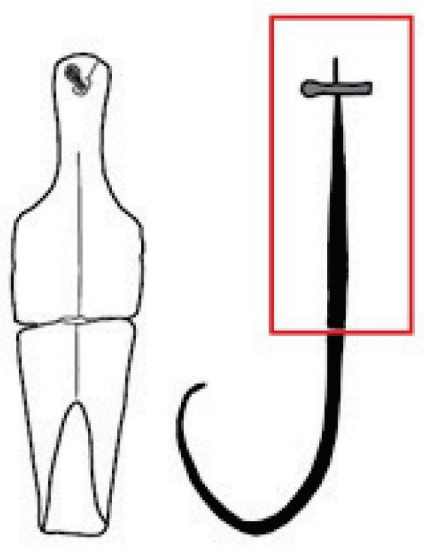

Tomb 155.21

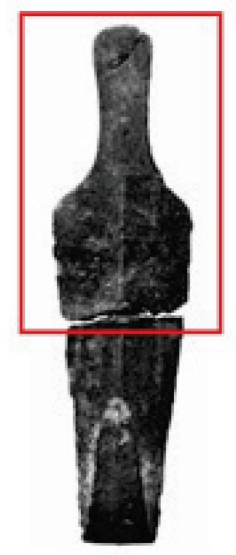

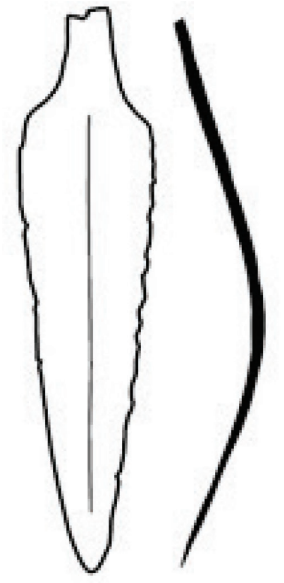

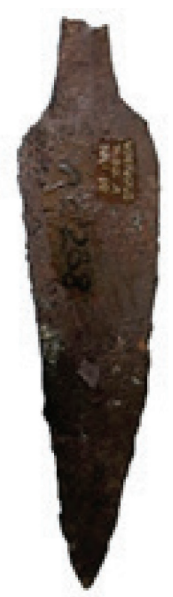

Tomb 85A.10

\begin{abstract}
0
$10 \mathrm{~cm}$

Fig. 2. Two knife blades, IA 2.525 (left) and IA 2.268 (right), from the Stewart excavations at Bellapais Vounous [4]. For IA 2.525, only the section illustrated within the red boundary was available for study while the severely bent section of the blade was lost some time after photographic recording for reference 4.
\end{abstract}

\title{
Samples
}

Two knives from the Australian Institute of Archaeology, AIA, Vounous artefacts IA 2.525 and 2.268 (Fig. 2), were submitted for neutron diffraction residual stress study and chemical analysis at the Australian Nuclear Science and Technology Organisation, ANSTO. Both knives were found bent in situ. Artefact IA 2.525 was bent through $180^{\circ}$ and was found fractured. Artefact IA 2.268, was bent to approximately $40^{\circ}$ at the mid-section of the blade. 


\section{Elemental characterization of IA 2.525 and IA 2.268}

The chemical compositions of the two Vounous knives were determined by combined Proton Induced X-Ray Emission spectroscopy (PIXE) and Proton Induced Gamma-ray Spectroscopy (PIGE) using $2.5 \mathrm{MeV}$ proton beam at the ANSTO Centre for Accelerator Science. The chemical analyses of other Vounous artefacts studied in work of Webb et al. [1] and Craddock [8] demonstrated that the majority of blades analyzed were essentially $\mathrm{Cu}$-As alloys with, usually, 2.5-5 wt.\% As. The two Vounous blades studied in this work were significantly different alloys, with As $<0.5 \mathrm{wt} \%$; IA 2.525 contained $1.30 \mathrm{wt} \% \mathrm{Zn}$ and only a trace of Sn and IA 2.268 contained $0.56 \mathrm{wt} \% \mathrm{Zn}$ and $0.66 \mathrm{wt} \%$ Sn.

The absence As suggests that the knifes were struck from a low As indigenous copper ore. With the arsenic content of IA 2.525 and IA 2.268 at $<0.5 \mathrm{wt} \%$, much lower than threshold of $2.0 \mathrm{wt} \%$, which some archaeologists believe is an indicator of deliberate alloying with this element, the ability to develop a hardened cutting edge would have been limited. As modern chemical analyses have shown, for copper blades from Cypriot Early/Middle Bronze Age sites, including Vounous, As was most likely added as an ore in the smelting process the result of which aided casting and increased propensity for work hardening [11]. The presence of $\mathrm{Zn}$ in IA 2.525 confirms an earlier analysis reported in Stewart and Stewart [4]. Balthazar [9] and other researchers have noted the presence of $\mathrm{Zn}$ in some Early/Middle Bronze Age artefacts but no conclusions about its presence have been drawn, other than questioning some earlier analytical methods. Further chemical analyses of Cypriot artefacts in Australian institutions are proposed and these may provide additional insights regarding $\mathrm{Zn}$ and other elements as alloying elements.

\section{Neutron residual stress measurements}

The residual stresses within the two Vounous knives were determined using the ANSTO KOWARI neutron stress diffractometer. [12]. Neutron diffraction stress measurements were undertaken at three gauge locations (L1, L2 and L3) on IA 2.268 (Fig. 3) and at one location (L1) on IA 2.525 (Fig. 4), to determine the stress profiles through each of the blades. With thickness of the blades varying from 1 to $2 \mathrm{~mm}$, through-thickness stresses were measured with a relatively high spatial resolution of 0.1 $\mathrm{mm}$ in through-thickness dimension. The strongest $\mathrm{Cu}(311)$ reflection was used for the residual stress measurements at wavelength of $1.55 \AA$. A gauge volume of $0.1 \times 0.1 \times 10 \mathrm{~mm}^{3}$ was used for the measurements in the three principal directions (longitudinal, normal and transverse) at the central line of the blades, at L1 and L2, however for measurements in the thinnest section of IA 2.268 the gauge volume, at $\mathrm{L} 3$, was reduced to $0.1 \times 0.1 \times 7 \mathrm{~mm}^{3}$.

To fully resolve the stress state, a zero normal stress condition was used to calculate stresses with high accuracy at the same time making possible non-destructive determination of each lattice parameter $\mathrm{d}_{0}$ of the alloy. A large number of measurement points through thickness, 9-13, with 0.1 mm steps, was considered necessary to determine several possible contributions to the total residual profile (hot forging, cold hammering, bending, etc.) which were resolved and separated. With measurement time of only 10-20 minutes per through-thickness position, a strain accuracy of 50 $\mu$ strains was routinely achieved.

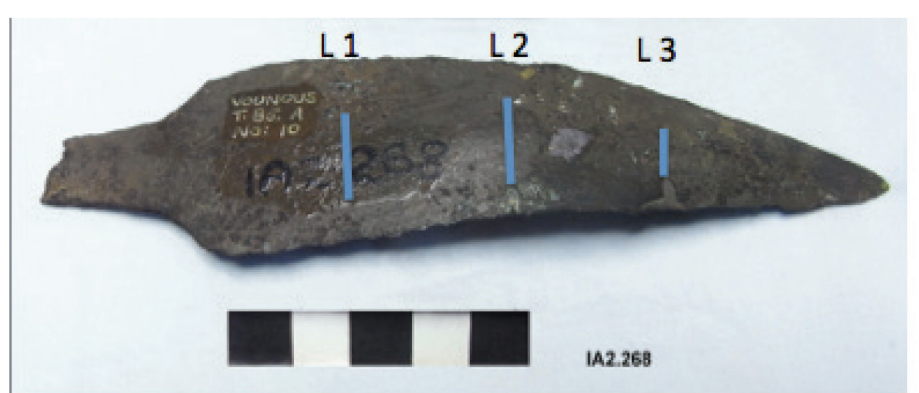

Fig. 3. Approximate locations of the three positions used for residual stress measurements of IA 2.268 .

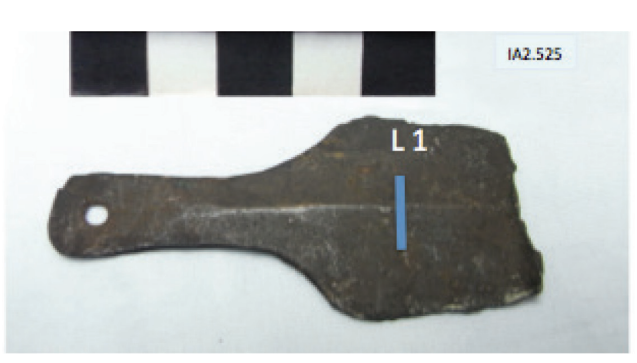

Fig. 4. Approximate locations of the position used for residual stress measurements of IA 2.525 


\section{Results and discussion}

The results of the residual stress measurements at the gauge locations L1, L2 and L3 for IA 2.268 are shown in Fig. 5 a,b,c and for gauge location L1 for IA 2.525 in Fig. 6.
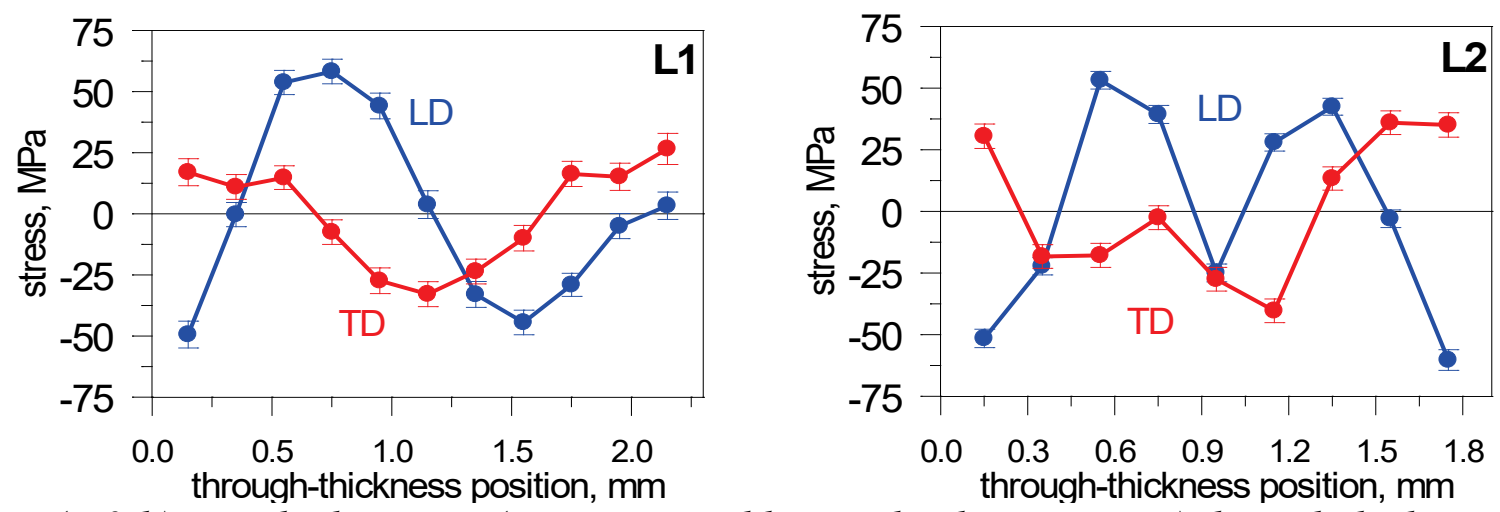

Fig. $5(a \& b)$. Residual stresses (transverse and longitudinal components) through thickness of knife IA 2.268 at positions L1 and L2.

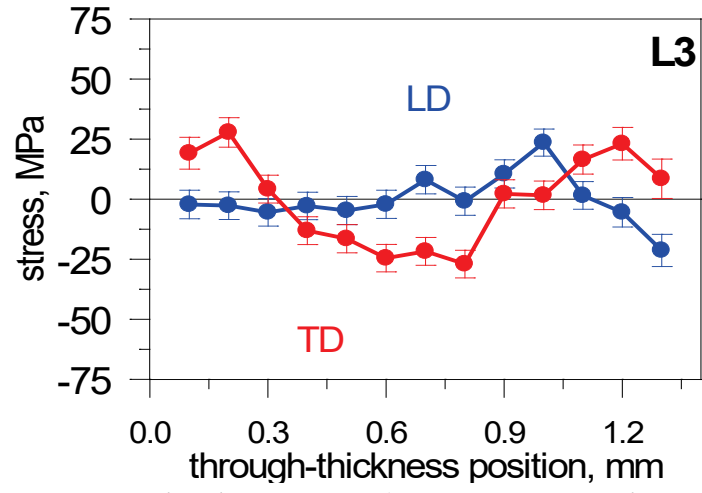

Fig. 5c. Residual stresses (transverse and longitudinal components) through thickness of knife IA2.268 at position L3.

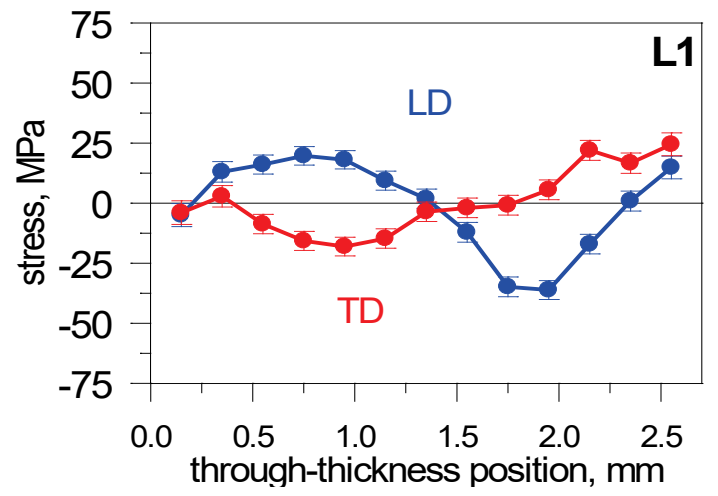

Fig. 6. Residual stresses (transverse and longitudinal) through thickness of knife IA 2.525 at position L1.

The through-thickness residual stress profiles of the transverse direction are similar for both blades and all locations. However, the transverse component of the thicker knife IA 2.525 at position L1 seems to incorporate also a bending stress component (slope) that is superimposed by the surrounding parts of the blade other than the location of measurements. Assuming that the plastic bending in the blades does not significantly affect the other stress components, most likely it is representative of the pre-bending treatments that can be associated with combination of hot forging

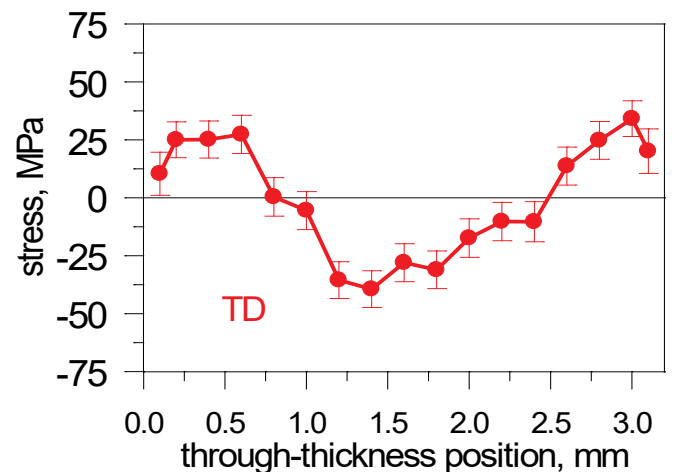

Fig. 7. Transverse component residual stress profile of a hot rolled $\mathrm{Cu}$ strip.

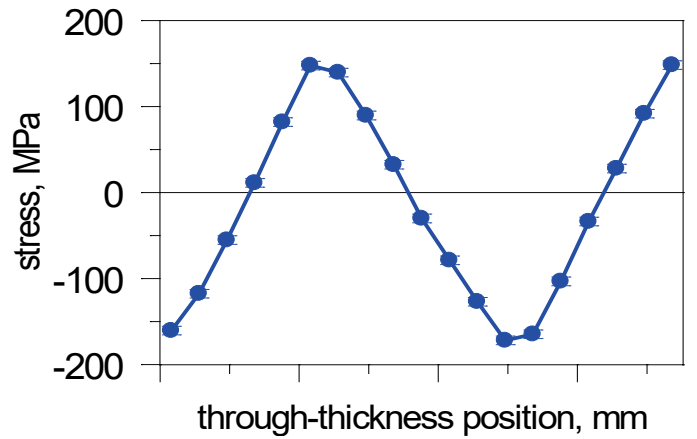

Fig. 8. Longitudinal component residual stress profile of a cold bent Al plate. 
or hammering (producing typical U- or V-shape stress profiles) and surface cold hammering (producing flattening of the stress profiles close to the surfaces due to compressive peening contributions). A contemporary analogue of a similar production route is given in Fig. 7. Therefore, the results show the expected route of production of similar bronze blades with possible heating and hammering a cast metal blank into shape as discussed below.

The through-thickness profiles of the longitudinal stress components are clearly a sequence of bending applied to both samples. A typical for bending "z-shaped" profile of the longitudinal component (Fig. 8) appears in the thickest part (L1) of the both blades. Thus, the through-thickness residual stress profiles of the longitudinal direction strongly indicate that the blade had been bent in the cold state. The longitudinal stress profile in the location of maximum curvature (L2) is most probably indicative of double bending, although the experimental data might be affected by microstructural variations and casting defects. This could be resolved at a later time through metallographic studies although currently this is not planned. Neutron imaging methodologies may also prove effective in identifying highly deformed material and the presence of inclusions, Cartechini et al [13].

Finally, the thinnest part of the bent knife IA 2.268, L3 evidently does not show the same bending pattern as for the thick part but rather bending in the opposite direction suggesting that the bending support point was between the point of maximum bending and the location of measurements. Alternatively, the profile could be interpreted rather as an evidence that one side of the blade (right side in Fig. 5a) was worked by forging/hammering at ambient temperature as the last episode of the treatment producing compressive zone in the surface region balanced by tension zone but most likely this treatment would produce the same feature in the transverse component that is not corroborated by the experimental data at L2.

Overall, the residual stress signatures for IA 2.525 at L1 and IA 2.268 at L1 were similar and consistent (although sample IA 2.268 is represented with just one profile) and suggested that both blades were subjected to bending at ambient temperature after fabrication.

\section{Historical context}

Webb and Frankel [2] p 132 note, (the) "Intentional breakage or distortion of copper-based spearheads and knives clearly occurred across Cyprus during the Early and Middle Bronze Age. While the practice was not universal, the number of examples is by no means insignificant." Their analysis showed that, of the knives excavated from Early/Middle Bronze Age sites, some 22.3\% of 301 known knives from Early/Middle Bronze Age burials were bent to greater or lesser degrees, and of interest is that $33.8 \%$ of the knives recovered at Vounous, were damaged in some way. It is, of course, possible that some of the damage was accidental and residual stress measurements will not differentiate this aspect of damage, particularly where there are only small amounts of bending, possibly for bends of up to 20 degrees.

The residual stress results of IA 2.268 and IA 2.525 does not contradict the suggestion by Balthazar [9] based on metallographic evidence that the knife blades had been forged or hammered from what was most likely a "blank" (as cast) to achieve the final shape with evidence of annealing after hammering. This is also consistent with the results of excavations at other Early/Middle Bonze Age Cypriot sites, such as Sotira Kaminoudhia [14] where both a dagger and cast blank for a dagger were found. Casting moulds for ingots have been found at Alambra Mouttes and Marki Alonia [15].

The residual stress results suggest that the objects were not knives specifically made as burial objects, but rather normal functional tools with work hardened blades. The knives IA 2.268 and IA 2.525 may have been used at or around the site of Vounous, but certainly, as functional tools, they must have had sufficient significance to be included in burials that warranted "removal" of the knives from utilitarian circulation. Knife IA 2.268, for example, was most probably of significance to either the person buried in Tomb $85 \mathrm{~A}$ or/and as part of a burial ritual. Additionally, the deliberate damage to the knife blade by bending suggests that the functionality of the blade was destroyed or disabled prior to its deposition in the tomb. As deliberate damage is observed across a number of Early/Middle Bonze Age burial sites this suggests a consistent burial practice or ritual, see [1, 7] for discussions on this matter. 


\section{Summary}

This preliminary study of residual stresses in two Bronze Age knives from the Australian Institute of Archaeology collection was undertaken using the KOWARI neutron diffractometer at ANSTO. The results provided evidence for the hammered "working" of one blade edge of one of the knives and suggested that both knives were subjected to bending after fabrication.

This information, when used with data from Vounous and other similar sites and other compositional and metallurgical analyses, provide a basis for placing these artefacts within Early/Middle Bronze Age material and social context, particularly their use in burials as part of mortuary practices.

This work has demonstrated the value of using neutron diffraction residual stress measurements for the non-destructive study of ancient metallic artefacts, which is particularly important from a cultural heritage and artefact preservation perspective.

\section{References}

[1] J.M. Webb, D. Frankel, Z.A. Stos, N. Gale, Early Bronze Age metal Trade in the Eastern Mediterranean. New Compositional and Lead Isotope Evidence from Cyprus. Oxford Journal of Archaeology, 25 (3) (2006), pp. 261 - 288. http://dx.doi.org/10.1111/j.1468-0092.2006.00261.x

[2] J.M. Webb, D. Frankel, Coincident Biographies, Bent and Broken Blades in Bronze Age Cyprus. in K. Harrell, J. Driessen, (Eds.) Contextualising Intentional Destruction of Objects in the Bronze Age Aegean and Cyprus, Publ. Louvain, 2015, pp. $117-142$.

[3] P. Dikaios, The Excavations at Vounous Bellapais in Cyprus, 1931-2, Archaeologia 88 (1940), pp. 1-174. http://dx.doi.org/10.1017/S0261340900014557

[4] E. Stewart, J. R. Stewart, Vounous 1937 -38. Field Report on the Excavations Sponsored by the British School of Archaeology at Athens. Publ. Lund, 1950.

[5] P. Åström, Intentional destruction of grave goods, in: R. Laffineur (Ed.), Thanatos. Les coutumes funéraires en Egée à l'Age du Bronze (Aegaeum I), Liège, 1987, pp. 213-217.

[6] G. Georgiou, J.M. Webb, D. Frankel Psematismenos-Trelloukkas. An Early Bronze Age Cemetery in Cyprus, Publ. Department of Antiquities, Nicosia, 2011.

[7] P. Keswani Mortuary Ritual and Society in Bronze Age Cyprus, Monographs in Mediterranean Archaeology, No. 4, Equinox Publishing, London and Oakville, 2004.

[8] P.T. Craddock, Report on the composition of metal tools and weapons from Ayia Paraskevi, Vounous and Evreti, Cyprus in: A Catalogue of Cypriot Antiquities in the Birmingham Museum and Art Gallery, Birmingham, 1981.

[9] J.W. Balthazar, Copper and Bronze Working in Early through Middle Bronze Age Cyprus Studies, Mediterranean Archaeology and Literature, Pocket Book 84, Paul Åström’s Förlag, Götebörg, 1990.

[10] S. Siano, L. Bartoli, J.R. Santisteban, W. Kockelmann, M.R. Daymond, M. Miccio, M., G. De Marinis, NonDestructive Investigation Of Bronze Artefacts From The Marches National Museum Of Archaeology Using Neutron Diffraction, Archaeometry, 48 (1) (2006), pp. 77-96. http://dx.doi.org/10.1111/j.1475-4754.2006.00244.x

[11] H. Lechtman H. Arsenic Copper: Dirty Copper or Chosen Alloy? A View from the Americas, Journal of Field Archaeology, 23 (4) (1996), pp 477 - 514.

[12] O. Kirstein, V. Luzin, U. Garbe, The Strain-Scanning Diffractometer Kowari, Neutron News, 20 (4) (2009), pp. 34-36.

[13] L. Cartechini, R. Arletti, R. Rinaldi, W. Kockelmann, S. Giovannini, A. Cardarelli Neutron scattering material analysis of bronze Age metal artefacts, Journal of Physics of Condensed Matter, 20 (2008), pp. 1-8. http://dx.doi.org/10.1088/09538984/20/10/104253

[14] S. Swiny, G. Rapp. E. Hersher, E. (Eds.), Sotira Kaminoudhia: An Early Bronze Age Site in Cyprus, Cyprus American Archaeological Research Institute Monograph Series, Vol. 4, American Schools of Oriental Research, Boston, 2003.

[15] A.B. Knapp, Metallurgical production and Trade on bronze Age Cyprus: Views and Variations in: V. Kassianidou, G. Papasavvas (Eds.) Eastern Mediterranean Metallurgy and Metalwork in the 2nd Millennium B.C., Publ. Oxbow, 2009, pp. 14 -125 . 